\title{
When pigs fly: Early endoscopy after esophagectomy is safe
}

\author{
Shamus R. Carr, MD, FACS
}

\author{
From the Division of Thoracic Surgery, Department of Surgery, University of Maryland School of Medicine, \\ Baltimore, Md \\ Disclosures: Author has nothing to disclose with regard to commercial support. \\ Received for publication May 7, 2017; accepted for publication May 11, 2017; available ahead of print June 20, \\ 2017. \\ Address for reprints: Shamus R. Carr, MD, FACS, Division of Thoracic Surgery, University of Maryland School \\ of Medicine, 29 S Greene St, Suite 504, Baltimore, MD 21201 (E-mail: scarr@ som.umaryland.edu). \\ J Thorac Cardiovasc Surg 2017; 154:1159-60 \\ $0022-5223 / \$ 36.00$ \\ Copyright (C) 2017 by The American Association for Thoracic Surgery \\ http://dx.doi.org/10.1016/j.jtcvs.2017.05.026
}

The reported anastomotic leak rate, regardless of technique, after esophagogastrectomy is $12 \%$ to $13 \%$. $^{1}$ Once this complication occurs, the hand wringing begins. Surgeons fret over all aspects of the leak: contained, not contained, drained, big, small, early, or late. In general, the algorithm routinely boils down to nothing by mouth and tube feeds versus esophageal stenting. There is increasing evidence of the value of esophageal stents in these patients. ${ }^{2}$ The common concern, however, is whether the endoscopy will make the anastomotic leak worse or injure the conduit.

There is no substitute for a skilled endoscopist, something that all thoracic surgeons who perform esophagectomy should strive to become. Although Dr James Luketich's group in Pittsburgh has not published on this subject, upper endoscopy is used by them in the early postoperative course for concerns with the conduit or anastomosis. My recollection is that we gained significantly more information from these early endoscopies than we caused injury; however, memories and recollections are no match for peer-reviewed publications.

Erkman and colleagues ${ }^{3}$ are to be commended for embarking on a project to provide data on a common question facing thoracic surgeons daily: Would early endoscopy after esophagectomy cause injury to the conduit or anastomosis? In the well-designed animal model study reported in this issue of the Journal, Erkman and colleagues $^{3}$ measured both intraluminal pressure and flow in the gastroepiploic artery during maximum insufflation during endoscopy in a gastric conduit after esophagogastrectomy. They were able to show that maximum insufflation neither affected blood flow to a point that would be detrimental to the conduit nor generated an intraluminal pressure that would disrupt the anastomosis. Some would argue that a limitation of this study is that it was done in a porcine model. This is actually not a limitation, because the anastomosis that was used is routinely created. A true limitation is that the anastomosis had just been performed, so it cannot be extrapolated into the days that follow. This is actually, however, also an unrecognized strength of this study. This study should give surgeons the confidence to perform endoscopy routinely to inspect the newly created pneumostatic.

\section{References}

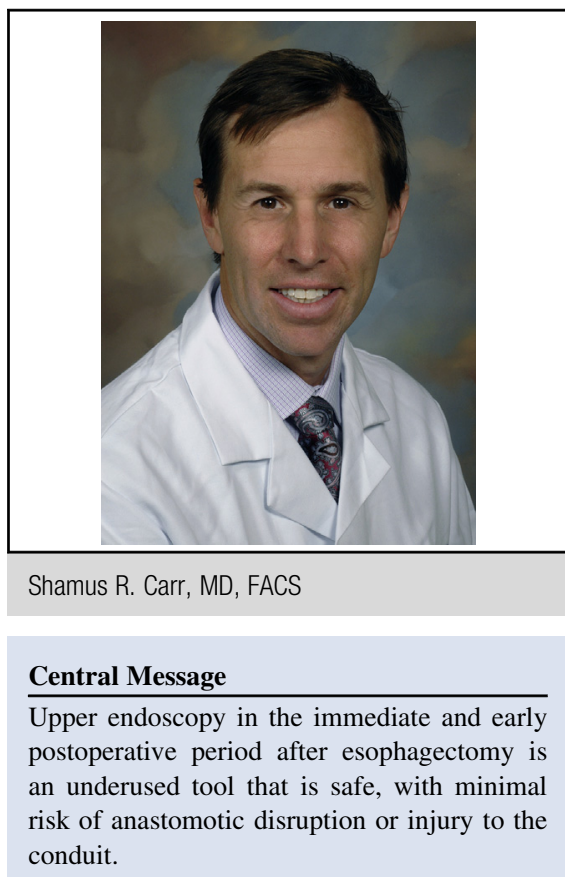

See Article page 1152 .

anastomosis at the conclusion of the case before closure. Endoscopy with insufflation at this point can help ensure that there are no technical problems amenable to immediate correction, which otherwise would present as a leak in the future. It also allows evaluation of the mucosa of the conduit. Current technologies are being used in an attempt to demonstrate adequate blood supply to the distal conduit. ${ }^{4,5}$ Endoscopy may be able to answer the same question while ensuring that the anastomosis is

Until a conduit and anastomosis can be created in a standardized fashion that reduces the nationally reported leak rates to the low single digits, every effort should be made to ensure that patients leaving the operating room after esophagectomy have the best chance for an uneventful postoperative course. Endoscopy at the conclusion of the case may help achieve this goal, and this article by Erkman and colleagues ${ }^{3}$ appears to show that it can be done safely.

1. Sihag S, Kosinski AS, Gaissert HA, Wright CD, Schipper PH. Minimally invasive versus open esophagectomy for esophageal cancer: a comparison of early surgical outcomes from the Society of Thoracic Surgeons National Database. Ann Thorac Surg. 2016;101:1281-8; discussion 1288-9.

2. D'Cunha J, Rueth NM, Groth SS, Maddaus MA, Andrade RS. Esophageal stents for anastomotic leaks and perforations. J Thorac Cardiovasc Surg. 2011;142:39-46.e1. 
3. Raman V, Moodie KL, Ofoche OO, Kaiser LR, Erkmen CP. Endoscopy after esophagectomy: safety demonstrated in a porcinemodel. J Thorac Cardiovasc Surg. 2017;154:1152-8.

4. Koyanagi K, Ozawa S, Oguma J, Kazuno A, Yamazaki Y, Ninomiya Y, et al. Blood flow speed of the gastric conduit assessed by indocyanine green fluorescence: new predictive evaluation of anastomotic leakage after esophagectomy. Medicine (Baltimore). 2016;95:e4386.

5. Campbell C, Reames MK, Robinson M, Symanowski J, Salo JC. Conduit vascular evaluation is associated with reduction in anastomotic leak after esophagectomy. J Gastrointest Surg. 2015;19:806-12. 